Marcus J. Schultz

Mart J. de Graaff

Michael A. Kuiper

Peter E. Spronk

\section{The new Surviving Sepsis Campaign recommendations on glucose control should be reconsidered}

Accepted: 23 January 2008

Published online: 20 February 2008

(C) The Author(s) 2008

An author's reply to this comment is available at: http://dx.doi.org/ 10.1007/s00134-008-1028-5.

Sir: Dellinger et al. are to be congratulated on their new Surviving Sepsis Campaign recommendations as published recently in this journal [1]. The efforts of Dellinger and his group are of great value for all of us who take care of patients with sepsis. Indeed, guidelines like those from the Surviving Sepsis Campaign, an initiative of the European Society of Intensive Care Medicine, the International Sepsis Forum, and the Society of Critical Care Medicine, are very much welcomed and appreciated by the intensive care community. They have been and continue to be an important tool in improving care of septic patients globally.

However, in our opinion, the new recommendations are flawed with respect to glucose control. The new recommendations for septic patients advise maintaining the blood glucose concentration (BGC) below $150 \mathrm{mg} / \mathrm{dl}(8.3 \mathrm{mmol} / \mathrm{l})$ instead of adhering to the more strict thresholds as in the two randomized controlled trials by van den Berghe et al. (BGC 80-110 mg/dl, 4.0-6.1 mmol/l) [2, 3]. The Surviving Sepsis Campaign justifies this departure on several grounds: new studies show conflicting results incidence of severe hypoglycemia with lower BGC thresholds, with a presumed association between severe hypoglycemia and death. We disagree with the advised thresholds, and argue against the reasoning for not retaining the original stricter $\mathrm{BGC}$ thresholds.

First, the evidence. Simply, there are no studies that provide evidence for glucose control in sepsis using the now recommended threshold of $150 \mathrm{mg} / \mathrm{dl}$. Using the $150 \mathrm{mg} / \mathrm{dl}$ upper limit, more septic patients will be in the higher BGC range. However, with more successful glucose control (i. e., BGC closer to $80 \mathrm{mg} / \mathrm{dl}$ ) more benefit is achieved [4, 5]. Indeed, the lowered $\mathrm{BGC}$ rather than the insulin dose is related to reduced mortality, critical illness polyneuropathy, bacteremia, and inflammation [4].

Second, the conflicting information that comes from new (yet unpublished) studies [6, 7]. Unfortunately, the multicenter VISEP trial on glucose control in Germany by the SepNet group was discontinued prematurely because of identical mortality rates in the treatment groups but a higher incidence of hypoglycemia in the glucose control group $(12.1 \%$ vs. $2.1 \%$ ) [6]. Another study, the European GLUControl trial, was also stopped before inclusion was completed [7]. As in the VISEP study, the primary reason for stopping inclusion of patients was the relatively high incidence of hypoglycemia in the glucose control group. Due to the early termination of these studies we are left with two underpowered randomized controlled trials which can by no means be used as evidence in the discussion on potential benefit of glucose control.

Third, blood glucose control with insulin carries the risk of hypoglycemia. Indeed, the incidence of severe hypoglycemia (defined as a blood glucose concentration
$<40 \mathrm{mg} / \mathrm{dl}$ ) is 5 to 10 times higher than with a conventional blood glucose strategy $[2,3]$. Thus, the rise in incidence of hypoglycemia in the glucose control groups in the two newer studies as mentioned above was not surprising. Similar findings came from numerous other studies reporting on some form of glucose control (merely studies with a before-after design) [8]. Fear of severe hypoglycemia has, at least in part, hampered broad implementation of glucose control [8]. Although many ICUs have adopted some form of glucose control, frequently the applied glucose control regimens have higher thresholds than those used in the original studies. Of note, with higher BGC thresholds, the incidence of severe hypoglycemia does not differ greatly from that with more strict BGC thresholds [8].

Fourth, the assumed association between hypoglycemia and poor outcome. We recently analyzed the shortterm consequences (seizures, coma, and death) of hypoglycemia [9]. The hazard ratio for in-hospital death was 1.03 (95\% confidence interval $0.68-1.56 ; P=0.88)$ in patients with a first occurrence of hypoglycemia relative to the controls without hypoglycemia. Results were corrected for duration of intensive care unit admittance before hypoglycemia, age, sex, and Acute Physiology, Age and Chronic Health Evaluation II score at admission. In addition, no cases of hypoglycemia-associated death were reported.

Although the evidence for glucose control with strict thresholds does not yet support a grade A recommendation (based on the highest level of evidence), it does appear to be stronger than the evidence in support of a strategy of tolerating higher BGC thresholds. Most importantly, however, the only evidence we have supports a BGC threshold of $110 \mathrm{mg} / \mathrm{dl}$, not $150 \mathrm{mg} / \mathrm{dl}$. 
Open Access. This article is distributed under the terms of the Creative Commons Attribution Noncommercial License which permits any noncommercial use, distribution, and reproduction in any medium, provided the original author(s) and source are credited.

\section{References}

1. Dellinger RP, Levy MM, Carlet JM, Bion J, Parker MM, Jaeschke R, Reinhart $\mathrm{K}$, Angus DC, Brun-Buisson $\mathrm{C}$, Beale R, Calandra T, Dhainaut JF, Gerlach H, Harvey M, Marini JJ, Marshall J, Ranieri M, Ramsay G, Sevransky J, Thompson BT, Townsend S, Vender JS, Zimmerman JL, Vincent JL (2007) Surviving Sepsis Campaign: international guidelines for management of severe sepsis and septic shock: 2008. Intensive Care Med 34:17-60

2. Van den Berghe G, Wouters P, Weekers F, Verwaest C, Bruyninckx F, Schetz M, Vlasselaers D, Ferdinande P, Lauwers P, Bouillon R (2001) Intensive insulin therapy in the critically ill patients. N Engl J Med 345:1359-1367

3. Van den Berghe G, Wilmer A, Hermans G, Meersseman W, Wouters PJ, Milants I, Van Wijngaerden E, Bobbaers H, Bouillon R (2006) Intensive insulin therapy in the medical ICU. N Engl J Med 354:449-461

4. Van den Berghe G, Wouters PJ, Bouillon R, Weekers F, Verwaest C, Schetz M, Vlasselaers D, Ferdinande P, Lauwers P (2003) Outcome benefit of intensive insulin therapy in the critically ill: insulin dose versus glycemic control. Crit Care Med 31:359-366
5. Finney SJ, Zekveld C, Elia A, Evans TW (2003) Glucose control and mortality in critically ill patients. JAMA 290:2041-2047

6. Brunkhorst FM, Kuhnt E, Engel C, Meier-Hellmann A, Raggaler M, Quintel M, Weiler N, Grundling M, Oppert M, Deufel T (2005) Intensive insulin in patients with severe sepsis and septic shock is associated with an increased rate of hypoglycemia results from a randomized multicenter study (VISEP). Infection 33:19-20

7. National Institutes of Health. Glucontrol study: comparing the effects of two glucose control regimens by insulin in intensive care unit patients. http://clinicaltrials.gov/show/ NCT00107601 [accessed October 2007]

8. Schultz MJ, Royakkers AA, Levi M, Moeniralam HS, Spronk PE (2006) Intensive insulin therapy in intensive care: an example of the struggle to implement evidence-based medicine. PLoS Med 3:e456

9. Vriesendorp TM, DeVries JH, van Santen S, Moeniralam HS, de Jonge E, Roos YB, Schultz MJ, Rosendaal FR, Hoekstra JB (2006) Evaluation of short-term consequences of hypoglycemia in an intensive care unit Crit Care Med 34:2714-2718
M. J. Schultz (®) · M. J. de Graaff University of Amsterdam, Department of Intensive Care Medicine, Academic Medical Center,

C3-415 Meibergdreef 9, 1105 AZ

Amsterdam, The Netherlands e-mail: m.j.schultz@amc.uva.nl; m.j.schultz@compaqnet.nl

\section{A. Kuiper}

Medical Center Leeuwarden, Department of Intensive Care Medicine,

Leeuwarden, The Netherlands

\section{P. E. Spronk}

Gelre Hospital, Location Lukas, Department of Intensive Care Medicine, Apeldoorn, The Netherlands 